\title{
Consuming dystopic places: What answers are we looking for?
}

\section{Introduction}

The Chernobyl Exclusion Zone is usually described as an abandoned, ghostly area, where silence has much to say. It tells a story of the night when hydrogen and graphite explosions scattered nuclear fuel and radioactive debris across a large part of Europe, affecting not only humans but also plants, animals, air, soil, roads, houses. The people inhabiting the wider Chernobyl region were forced to fight against the invisible enemy for many months, and years, to come. The event changed their everyday lives, their identities, their presents and futures. Several decades after the disaster, however, the situation in the Zone has in many ways changed - it has been reclaimed by nature, repopulated by people and increasingly visited by tourists.

The Ukrainian government proclaimed the Zone safe for visitors and officially opened it for tourism in 2011 (Yankovska \& Hannam, 2014). Established guided one-day or multi-day tours offer small tourist groups a safe passage through the area. People visit for various reasons - journalism, research, photography, adventure, urban exploration, inspiration, or finding meanings of the place. Most visitors to the Exclusion Zone are driven by educational reasons, to learn more about the catastrophe and its aftermath. Urbexers and photographers are drawn to it by a desire to explore and document the abandoned, ruined places (Yankovska \& Hannam, 2014), while others want to visit the locations which are featured in movies or video games. There are also unofficial visits, paid by so-called 'stalkers' who cross 'the borders' and explore the place on their own. Whatever the reason for visitation, Pripyat, and the whole Zone, reveals itself to visitors and offers a whole new palette of sensations, recollections and imaginations.

Chernobyl has been the synonym of a dark place which maybe conceptualised as a dystopic dark tourism site. In general, dystopias are characterised by dehumanisation, tyrannical governments, or environmental disaster, or may have other characteristics associated with a cataclysmic decline in society. The fictional dystopic worlds, like that depicted in Orwell's 1984 with inherent paranoia and omnipresent governmental surveillance, are mainly created to warn people of impending dangers (Podoshen et al, 2015b). Chernobyl, which has not only become a metaphor for environmental disaster but also for an implosion of the political 
system, can by all means be described as a dystopic place to which tourists, prompted by the recent screening of the $\mathrm{HBO}$ miniseries, are now increasingly flocking.

The present paper thus locates the Chernobyl Exclusion Zone within the dark tourism discourse and conceptualises it as a dystopic tourism site. In doing so, it extends the work of Podoshen et al (2015b) who laid grounds for examination of dystopia as an underlying feature of destinations and a pull factor for tourists. Furthermore, the paper goes beyond the hegemonic qualitative methods in dark tourism explorations, instead examining the embodied ways in which human experiences are constructed and negotiated on commercial tours in the Zone. It suggests hermeneutic phenomenology as an approach that can uncover the embodied dimensions of the on-site encounter. To that end, I aim to explore what it is like to be in a dystopic, yet increasingly touristified, place utilising Interpretative Phenomenological Analysis (IPA), an approach that is not only well-established in qualitative phenomenological psychology but is also novel in tourism. Ultimately, the paper aims to add to the debate around people's intimate experiences of dark, dystopic tourism sites in relation to a wider context of being in and perceiving the world and sheds some light on new approaches to studying and managing the tourist experiences in dark tourism context. Turning attention to the Chernobyl Exclusion Zone, I here illustrate that in taking the bodily agency of those who consume dystopic, albeit to an extent commodified places, we can deepen understanding of the human experience and the ways they can be enhanced by tour operators and facilitated by guides that are conducting tours and curating the 'dark sites'. The paper concludes with a broader discussion concerning the ways situated knowledge is crucial to unpacking the complexities of commodified dark tourism sites and the processes in which the tourist experience is constructed, negotiated and delivered.

\section{The dark tourism scholarship}

Dark tourism is an established concept within the tourism scholarship. It is related to any form of tourism that is associated with death, disaster, suffering, atrocity, tragedy or crime (Light, 2017; Lennon \& Foley, 2000; Sharpley, 2009; Stone, 2006; Cole, 2000). It remains fuzzy, however, as the concept has many shades and has been conceptualised in multiple ways (Sharpley, 2009). Some of the sub-forms of dark tourism encountered in the literature include prison tourism (Strange \& Kempa, 2003); genocide tourism (Beech, 2009; Dunkley 
et al., 2007), grief tourism (Lewis, 2008), disaster tourism (Robbie, 2008), suicide tourism (Miller \& Gonzalez, 2013), thanatological tourism (Yan et al, 2016), atomic tourism (Freeman, 2014), dystopian dark tourism (Podoshen, 2013; Podoshen, et al, 2015a, Podoshen et al, 2015b), post-disaster tourism (Martini \& Buda, 2018) or conflict zone tourism (Buda et al, 2014). It has also been associated with paranormal tourism (Pharino et al, 2018) while the term 'dark rides' has been recently used in describing the consumption of hyperreal experiences in theme parks (Langhof and Güldenberg, 2019). Light's (2017) extensive review of the research in dark tourism over the past two decades suggests that the vast majority of published work is related to wars, battlefields, graveyards, concentration camps or prisons. However, some of its conceptualisations do not necessarily involve death, but rather visits to inaccessible, forbidden or potentially dangerous places (Buda \& Shim, 2015) or partaking in commemorative events (Kennell et al, 2018).

Within the dark tourism scholarship, new ways of knowing the concept have been called for. For example, Podoshen et al (2015b) suggested that researchers should move beyond positivist approaches and would benefit from novel insights into dystopian and dark tourism experiences. To that end, scholarly attention has shifted towards a closer understanding of the motivations for undertaking journeys in order to gaze upon the sites or learn about the 'dark events' that occurred in the past (Podoshen, 2013; Dunkley et al, 2011). Despite the growing interest in people's visitation of these sites, however, not much work has been done in terms of the "motives, expectations and experiences of such tourists" (Light, 2017, p. 279). Dark places are consumed through people's bodies, emotions, affects, thoughts, and social, cultural and spatial interactions. The body is an instrument of knowing the dark sites and a catalyst for bonding to and understanding the place. And yet, tourists' embodied experiences have received limited attention. For this reason, Martini and Buda (2018) draw attention to tourism scholars to theorise dark tourism as an affective socio-spatial encounter. In responding this call, Buda et al (2014) bring together emotional, affectual and sensuous geographies in examining dark tourism and argue that tourism studies should pay closer attention to the politics of feelings in this context. In dark tourism, they argue, feelings and emotions matter; what is felt is both imagined and material, individual and collective, and have the power to inform the ways in which tourism and tourist experiences are managed in dark places.

This study, therefore, aims to phenomenologically explore and discuss what it is like to be there, in this seemingly highly contaminated, post-apocalyptic, dystopian microcosm, the first 
association of which is silence, grimness, hollowness and stillness. It is argued here however, that there is potential for deep and meaningful engagement with the dystopic place through embodied, affective and emotional encounters, which can make us ponder and prompt to more deeply think of our place within the world. I therefore explore the human experience by way of Interpretative Phenomenological Analysis, the method to which I will turn later.

\section{Chernobyl as a dystopic dark tourism site}

The Chernobyl disaster is considered the world's biggest nuclear accident; it occurred on $26^{\text {th }}$ April 1986 near the town of Pripyat, in the area of Ukraine that then belonged to the Soviet Union. Nuclear reactor 4 of the Chernobyl Nuclear Power Plant exploded during a safety test and spewed radioactive fallout over much of Europe. In only 36 hours more than 115,000 people were evacuated from the town of Pripyat and 180 villages in the region. The most radioactively contaminated area around the power plant was instantly placed under the military control and officially designated as the 'Chernobyl Nuclear Power Plant Zone of Alienation', known commonly as the 'Chernobyl Exclusion Zone' or simply the 'Zone'. The major psychological impact of the disaster was mainly due to fear of radiation effects. Jaworowski (2010) explained that "the worst harm to the population was caused not by radiation, and not to flesh, but to minds" (p. 149). After 33 years, there are still the fears and risks of radiation; however its levels have significantly decreased, and it is now safe to visit. Furthermore, a number of evacuated locals have returned to their villages, and the nuclear power plant workers are again inhabiting the Chernobyl town; but Pripyat, which used to be the largest town in the area, remains 'dead'.

Literally overnight, the town of Pripyat made its dramatic transition from being the 'Soviet utopia' to an utterly dystopic place, through a rapid process of evacuation and subsequent dehumanisation of the whole area. Before the accident, it had been known as the 'city of the future', purposefully built to accommodate the nuclear power plant workers and their families. It was a privilege to live in town as the monthly wage of workers was multiple times bigger than the national average. The town had more than 13,000 apartments, schools, stores and cafes, a cinema, a sports hall, cultural centre, several factories and a hospital. It was decorated with plants:18,136 trees, 249,247 bushes, and 33,000 rose bushes in order to make it the most beautiful town in SSSR (Pripyat, 2019). However, its identity has drastically changed in the years to follow the disaster. Now shrouded in silence and decay, it looks frozen in time (Dobraszczyk, 2010). It has been largely reclaimed by nature; what were once 
streets have become forest paths, and trees grow out of the windows of buildings and cracks in the road. The absence of humans gave way to the presence of wildlife that is now freely roaming around the area.

Since 1986, the consequences of the Chernobyl disaster have been widely documented across multimedia, literature and art. They have also received increased attention from academics and become the focus not only of life scientists but also humanistic and social scientists (Davies \& Polese, 2015; Petryna, 2013; Kuchinskaya, 2014; Bürkner, 2014). Although the event and its consequences have been extensively researched, previous studies on Chernobyl within the tourism context are rather scant. By way of example, the work of Philip Stone (2013) explored the phenomenon of touristification of Chernobyl. In suggesting that the place is both witnessed and consumed, real and imagined, he claims that these qualities have now become part of the tourist experience. Drawing on Foucault's concept of 'heterochronism', Stone conceptualised Chernobyl as a heterotopic place, a ritual space that exists outside of time, which accumulates time and witnesses an age. For this reason, he claims, tourists consume not only the disaster, but also its much wider context and the era in which the disaster occurred. Goatcher and Brunsden' (2011) study involved a cultural sociology iconographical analysis of tourist photographs in relation to the representation of anxiety in contemporary society. Furthermore, Yankovska and Hannam (2014) positioned their research within the dark tourism context and focused on explorations of people's motivations to visit as well as practices of tour guides in the process of construction of the tourist experience. And yet, explorations of the lived experiences of tourists visiting the Zone are greatly missing in the tourism literature.

Podoshen et al (2015b), building on Stone and Sharpley's (2008) claim 'making absent death present', introduced the Dark Tourism model, further expanding it by incorporating the cultural fascination with utopia/dystopia. The authors suggest that their "model provides a means to confront the inevitability of utopia gone awry that may or may not involve death (but often does). Utopia is a place many strive for, but never reach, and for many, utopia quickly becomes a nightmare." (p. 324). This perfectly resonates with the Zone, which in just seven years of its existence, Chernobyl transformed from the Soviet utopian world into an ultimately dystopic, contaminated and barren place. The strength of the model is its ability to allow for closer examination of tourists and their meaning making processes, insights into the emotional reactions to what the authors termed as dark aesthetics, and construction of the 
experience of various dystopic realities. Following this, I put forth a hermeneutic phenomenological approach that focuses on the affective and sensual encounters with the Chernobyl Exclusion Zone and the experiences that emerged from these interactions.

\section{Methodology}

Phenomenology, a philosophical area initially conceptualised by Edmund Husserl, Martin Heidegger, and Maurice Merleau-Ponty, has become increasingly popular in studying experiences in humanistic and social science disciplines (Pernecky \& Jamal, 2010). Although tourism researchers embraced phenomenology as a study perspective, they still seem to struggle to accept studies that are concerned with a small number of participants (see for example Malone et al, 2013). However, the prescribed sample size that used to be strictly followed in order to ensure rigour and achieve trustworthiness, has been overcome in recent years. Researchers have been increasingly disrupting the entrenched ways of doing research and adopting plural ontologies and more flexible methodologies in studying tourist experiences (Wilson \& Hollinshead, 2015). Phenomenological studies are usually idiographic, which enables a detailed analysis of single cases. One clear advantage of single person case studies is that they "offer a personally unique perspective on their relationship to, or involvement in, various phenomena of interest" (Smith et al, 2009, p. 29). Cognition lies at the heart of phenomenology, but it is a cognition that is "dynamic, multi-dimensional, affective, embodied, and intricately connected with our engagement with the world" (Smith et al, 2009, p.191). To that end, I embraced an idiographic hermeneutic phenomenological approach in aiming to explore the embodied tourist experience of being inside the Chernobyl Exclusion Zone.

Although phenomenological explorations in dark tourism are not new (Boateng et al, 2018; Podoshen et al, 2018), the Interpretative Phenomenological Analysis (IPA) is a road less travelled. To date, IPA studies have been conducted mostly in psychology; however in tourism they are very rare (see Malone et al, 2013). The IPA was a justifiably adequate methodological approach to this study. Initially proposed by Smith et al (1999), it represents a combination of psychological, interpretative, and idiographic components (Eatough \& Smith, 2008). Having an idiographic focus, it offers insights into how a given person, in a given context, makes sense of a given phenomenon, and is especially useful when one is concerned with complexity, process or novelty. It synthesises ideas from phenomenology and hermeneutics with the aim of exploring in detail how an embodied, situated person is making 
sense of their personal and social worlds. The biggest quality of an IPA study lies in gleaning the meanings particular experiences, events or emotional states hold for participants (Smith \& Osborn, 2003). It attends to all aspects of the lived experience, from the individual's wishes, desires, feelings, motivations, or belief systems through to how they are manifested. Eatough and Smith (2008) emphasise the bodily responsiveness, for example how one becomes aware of the sun's warmth and what it is like to experience it. I thus saw strength in this method as it allowed attention to be paid to a single participant and the multiple layers of his experience. To obtain the data I conducted an in-depth, semi-structured interview. I formulated questions in such way to prompt thinking of thoughts and bodily reactions whilst, for example, being inside the abandoned buildings, or the feelings and sensations that emerged while walking on once highly contaminated debris. The questions focused on exploring sensory perceptions, mental phenomena (thoughts, memories, associations, fantasies), and individual interpretations.

In general, IPA researchers concentrate more on depth and richness, rather than the breadth of the study (Smith, 2004). The study always begins with the particular and the personal, and argues for the intensive examination of the individual, not aiming to make general claims. The focus on the narratives of a single participant can therefore provide sufficient empirical material to inform the tourism theory in trustworthy and credible ways. Smith and Osborn (2003) claim that the power of IPA is judged by the light it sheds within the broader context, and not on the number of participants that took part in the study. A detailed analysis of a single case may well be justified if provides rich and meaningful data, and if the case is made for learning from the experiences of an individual (Smith, 2004). This study therefore extends the idiographic approach to studying the human experience through engaging with a single participant through the IPA and illuminating the benefits it holds in tourism explorations.

The empirical material therefore draws on experiences of one participant. I grant attention to the ways, meanings and experiences that unfolded during a tour of the Zone and the materialities and affordances that prompted them. De Jong's (2017) work was particularly helpful in my decision to explore the experiences of a single participant. Whilst I engaged in conversations with several people during the tour, William was chosen as the only person with whom I maintained sustained contact during and after the tour. He also agreed to engage in an interview post-tour in order to reflect on his personal lived experience of being in the Chernobyl Exclusion Zone. He decided to narrate his embodied encounters, rendering unique 
insights into how the materialities and affordances of the Zone were experienced from his own perspective. This allowed for intimate insights into the multiple and context-specific ways dystopic places were encountered and consumed (de Jong, 2017, p. 131).

I fully engaged with William in order to understand his observations, prompt further discussions and reflections and glean meanings from them. To analyse the data, I made use of double hermeneutics which assumed "making sense of the participant trying to make sense of what is happening to them" (Smith et al, 2009, p. 3). In other words, it was a dual interpretation process, because firstly I let William articulate his experiences and give them meanings, after which I tried to decode these meanings to make sense of his meaning making (Smith \& Osborn, 2003). The analysis required my sustained immersion in the data with which I worked in a dynamic, iterative and non-linear manner. The process of careful rereading of William's answers allowed me to code the data, group them together and later import theory to provide context for their discussion in broader tourism and social contexts (Eatough \& Smith, 2008).

William was not entirely unknown to me. We had known each other from before, which assumed somewhat easier access to his observations and interpretations of the experience. We shared love of otherworldly nature, abandoned places and industrial heritage. For this reason, we decided to visit the Zone together. Having arrived in Ukraine from different parts of Europe (Serbia and the UK) exactly on the day of disaster $\left(26^{\text {th }}\right.$ April 2019), William and I met in Kiev and joined a tour to the Zone. My presence allowed for much richer insights into social, spatial and temporal dimensions of the tour. Epistemologically, hermeneutic phenomenology is open to many possible interpretations and understandings, with the researcher being an intrinsic part of the interpretation, who cannot be bracketed out of the process (Pernecky \& Jamal, 2010). We conversed, took photographs and discussed what we were seeing and experiencing during the day. I was taking my notes during the trip, and later transferred them in a personal diary in more expressive ways. This I mention in order to justify the lengthy depictions of the environment through which we were passing, and through which I aimed to provide context for our conversations, which I disclose across the sections that follow. In the subsequent analysis of the empirical material, I distilled three broader themes that emerged from the data analysis: commodification of the Zone, the sensual engagement with the place, and the metaphysical questions that it instigated. I now turn to their discussion. 


\section{Commodification of the Zone}

The notions of death, suffering and disaster have been increasingly commodified and commercialised by the tourism industry through social media, destination marketing, museum exhibitions or on-site guided tours. By way of example, the Auschwitz-Birkenau concentration camp (Stone, 2012), Robben Island or Alcatraz prison in San Francisco (Strange \& Kempa, 2003), have become museums in their own right. Like Auschwitz, Chernobyl has become a 'tourist attraction' (Goatcher \& Bunsden, 2011). It has the elements of an open-air museum spreading across a large geographic territory (Virilio, 2007). Stone (2012) suggests that dark tourism sites demand somewhat different managerial approaches and interpretation, particularly in the Chernobyl Exclusion Zone in which the route is preplanned and behaviour of tourists are strictly managed. Most one-day tours include visits to several affected villages, the nuclear reactor 4 in its sarcophagus and other nuclear reactors in the area, the cooling pond, remains of the Red Forest, the town of Pripyat, Duga-3 early warning missile detector and the secret military town of Chernobyl. During the tour, a group normally has an 'atomic lunch' in the canteen number 9, with the authentic menu that workers had back in the 1980s.

We joined a group with Chernobyl tour (Chernobyl-tour.ua) in Kiev and set off north towards Belarus borders. We journeyed through the Ukrainian countryside and eventually reached the first checkpoint, "Dytiatky", at the entrance of the Chernobyl Exclusion Zone. Along the way, our guide gave us instructions on safety measures, introduced us to the code of conduct, and showed us a short documentary that depicted life in Pripyat before the disaster. We were advised not to touch anything while in the Zone, but rather to observe, as is the case in most museums where artefacts are viewed from the distance or through protective glass. Soldiers and workers at the powerplants and in the canteen, as well as certain buildings, must not be photographed. We were advised that walking is permitted only on concrete surfaces as vegetation carries much higher levels of residual radioactivity. Drinking water from ponds or eating food outside the van is strictly forbidden. The main danger, the guide explained, is not in the radiation itself, but in particles of radioactive material that may remain on clothes and for this reason three scans are performed during the tour.

Crossing the borders and entering the Zone required a ticket scan, passport check, and optional equipping with dosimetres and Geiger counters. When the group completed registration, the ramp lifted before us and the next moment we slid into the buffer zone. I 
remember the comment that William made at that very moment: "I'm very excited, I hope to see a radioactive bear, remember that bear from the movie Annihilation?'. Hearing him say that, I wanted to know what crossing the threshold between the 'safe zone' and the 'exclusion zone' was like for him. In his reflecting on the transition, he compared this experience with that of entering a theme park:

Entering the exclusion zone had an element of surreality to it. Chernobyl is such a known event, so studied and documented and entering the exclusion zone on a tour bus, swing and big-band music playing from the souvenir stand, was an odd experience. Though obviously this was tempered with excitement, a certain expectation of what to see. The spookiness and drama played up by pop culture and video games, the idea of Chernobyl as a setting, the exclusion zone a mis-en-scene for films, games, tv shows and endless documentaries makes it almost a kind of fiction, one I've know from a young age, so even when physically entering the place I felt an odd detachment, a sense that I was a tourist in some kind of theme park. I think with these eyes I felt almost a little irritated, as if our entering and that of the other tourists was some kind of desecration as if we should have been more solemn and dignified. I even remember thinking of Jurassic Park and the opening scenes of jeeps driving through the big branded gates on their dinosaur tour.

He paused and then added:

I had an ultimate sense of the ability of humans to make even the most colossal events and locations into some banal commodity. The image of Pripyat, and its wheel, is so appropriated by popular culture that I can't help but link it with video games and science fiction. But there it is, science fact, so close you can touch it.

Once the vehicle entered the Zone, the feeling slightly changed, however. The feeling of being in a theme park gave way to feelings of being in a real, as tangible as it can be, postapocalyptic place. All the props were there on display: the decayed industrial heritage, the remnants of the past community life and the political regime. There was the inevitable Soviet propaganda, as well as the slogans and symbols of the Soviet era, such as the hammer and sickle. Portraits and statues of Vladimir Lenin and the rusty state emblems of the Soviet Union were still lingering on the tops of concrete blocks of flats. An amusement park that was scheduled to open on $1^{\text {st }}$ May 1986 for the Mayday celebrations was still on display. The 
residential apartment buildings were filled with well-preserved posters, toys and stopped clocks. There was broken glass everywhere, rusty barbed wire, and unsupported floors and roofs. Gas masks, clothes, toys and textbooks in abandoned schoolrooms were scattered around. Although most of these objects were authentic and from within the Zone, some may have been positioned deliberately at certain places by tour organisers to better present them to tourists.

In moving through and interpreting the place, the guides' role was crucial. It was embodied in the interpretation of the people and events from the past and curation of the artefacts, as well as continual instruction of the group and their navigation through the Zone. Modlin et al (2011) posit that "the importance of space cannot be overlooked since the narrative meanings attached to places and the order in which they are toured shape the tourist experience and the ability to create affective connections with people from the past" (p. 15). At dystopic sites, the guide's role is therefore more than purely instrumental, it largely involves cultural brokering as well. The guides have agency in the process of meaning making through storytelling practices: they aim to evoke past events and foster emotional response in tourists. Although commodified and commercialised, the Chernobyl tour is more than a 'factual adventure' (Modlin et al, 2011). It is an empathetic, affective, emotive and sensual journey, the experience of which may be further heightened by guides' interpretation. For example, Modlin et al (2011), in arguing that guides are creators of empathy, explain that "a full understanding of the past requires people to adopt, cognitively, a perspective different from their own and to establish an emotional connection with historical actors from different eras and walks of life" (p. 4). The guide's role largely assumes encouraging tourists to connect to the place through the feeling of empathy, not only with the people that once lived there and that were forced to abandon their homes chased by the 'invisible enemy', but also with the societal conditions of the past era as well as the society in which we currently live. This echoes Stone's (2013) suggestion that tourists are consuming not only the disaster itself, but also the era in which the disaster happened.

\section{The sensual encounter}

During the tour, we entered abandoned houses, buildings, hospitals and kindergartens. They were ruined and looked haunted by the ghosts of the past. The spookiness and eeriness of the place were combined with the background silence, disturbed by overwhelming sights, sounds and smells. For example, in Zalissya, the first village we visited, our every step was followed 
by the cuckooing and chirping of sparrows, and we would occasionally entangle ourselves in cobwebs filling the spaces surrounding the abandoned houses. The interior of the hospital we entered was in a mess, the floor full of dirt and dust. We walked on the broken glass and wood, stepping among handwritten reports, scripts, test tubes, medication bottles and ampules that were scattered all over the floor. A strong medicinal smell was still very present, and the atmosphere of the past almost palpable. The old, rusty gynaecological bed appeared in front of us, and the sight of it, combined with the beeping sound of our Geiger counters, made the whole group stop to catch their breath.

It is claimed that embodied, sensual engagement is the way in which people interact with, understand and make sense of a place, which they inhabit or through which they move (Buda et al, 2018). For example, Dobraszczk's (2010) embodied experience of his trip to Chernobyl and Pripyat reports various pleasures and excitements: of surprise, amazement and delight in the textures, atmospheres and objects of his trip. This was particularly obvious in a space alien to us, that can be described with words such as contaminated, old, rusty, ruined, decayed, radioactive, or broken. The body was certainly perceiving it in somewhat different ways. Edensor (2007) explores the ways in which ruins offer alternative experiences in mobility and memory. He considers ruins as marginal urban spaces which offer a rich sensory experience, focusing on the visual, sonic and aromatic qualities of such spaces. The ruin, he explains, "feels very different to smoothed over urban space, rebukes the unsensual erasure of multiple tactilities, smells, sounds and sights" (Edensor, 2007, p. 227). Devoid of their function, their "aesthetic, shapely and textural qualities may be apprehended" (p. 223). The sensual engagement with such spaces depends upon materialities that have the power to constrain and enable a range of actions. The strong sensations experienced in the industrial ruins may be repellent but also delightful, for they provoke unexpected pleasures, imaginings and desires. The human body responds to the ruins whilst walking through them. The body needs to continually improvise in relation to the terrain and obstacles encounters along the way (Edensor, 2016), which adds to the whole experience of perambulations through the ruins as it opens up new sensorial horizons.

This overwhelmingly strong sensory response we had when we arrived in Pripyat, the ghost town that was entirely evacuated in only 36 hours after the explosion of the Nuclear Reactor 4. Walking along the street which holds the name of the Soviet atomic bomb creator, Igor Kurchatov, gave everyone shivers. I wanted to know how William felt whilst walking around 
the abandoned villages in the Zone and in the town of Pripyat. He provided a detailed and very vivid account, accentuating the sensory experiences:

"The smells were of old things, rotted wood and plaster. Damp, mould and spores. The smell of earth and pine, trees, clear fresh air, ozone. It was the smell of nature with that hanging overreaching smell of decay and deterioration. The smell of metal and earth combined. It is odd to say this, but I have smelled this before, when visiting the World War 1 trenches in Belgium and France, it is only on reflection now that I realise this, but it is the same smell, of old metal in the mud. I suppose they waged a war against radiation here. Man and machine tearing the ground to pieces just as happened on the battlefields. This background smell, as I call it, is as pervasive as the radiation but obviously more observable. It is a heavy smell, an all-enveloping haze, that even in remote areas, where vegetation and forest were thick, was noticeable."

"And how about inside the buildings", I asked.

"Within the buildings themselves, the smell was damper. It smelled like the shed in my parents' back garden before the new roof was put on. It smelled of barns and ruined buildings in rural England and Scotland. I could smell the mould from my grandfather's old canvas fishing bag and even some of those old family artefacts from generations ago. It is spooky to think so, but this smell I have also known from a nightmare that I have had in the past and still remember in snapshots. Incidentally this nightmare took place in a concrete building, disused like the Pripyat shopping centre, and situated within an encroaching forest. That is spooky. Or is it simply the smell of old things and past lives?"

Being there awakened the senses and brought together memories of the past through what is called the Proustian effect. Some tiny sensory stimuli, like the smell of sheds, barns and mould, transferred William not only back to the past, but also to his dreams, bringing back the lost memories. He further reflected on the sounds:

"The sound I remember most is the sound of broken glass underfoot. Permeating all is the continuous singing of birds. I will also never forget the wailing of the Geiger counters as we first stepped off the bus outside the irradiated kindergarten. It imparted an unnerving feeling of nausea. In one of the rooms of that building was ensconced 
quite a large wasp nest. In the room alone I heard alarms, wasps and singing birds. I felt on the edge of an apocalypse, as if this is how being near an apocalypse might feel, that humming of wasps reminded me of the buzzing of flies around corpses."

Furthermore, the encounter with an empty city carried some meanings. To William, it was aesthetically pleasing from the point of view of someone with a vivid imagination and a love of interesting places. The ruins of Chernobyl and Pripyat have been greatly aestheticised and appropriated for use in widely differing contexts (Dobraznyk, 2010). There was also a truly strong artistic element in the image of Pripyat which was adding to the elegance of the place. Many buildings were decorated with mosaics, and some even had stained glass and frescoes. Furthermore, street artists have been expressing their feelings through small paintings and murals covering the walls of the abandoned town. From screaming men and women to crying or lost children they truthfully depict the atmosphere of the place and the mood surrounding the past events. They are illustrative of the hopes and dreams, of lost childhoods, of the agony and horror that the inhabitants were forced into. Equally, illustrations of wildlife are common in the Zone. They indicate the repopulation of the animal species such as bears, lynx or moose and in a way celebrate the taking over of nature. The artistic work represented a visual delight for William, as if it was meant to be there:

I sympathised with the stalkers. To me, they seem like errant wanderers. I related to them. I don't see them as irresponsible. They are going into open spaces, seeking adventure and looking for meaning, but they don't make a big show of it. Their art seems personal and respectful, almost complimentary of the place.

The Zone appeared as a living organism, in its process of becoming. Through this process, the buildings, the bodies, the paintings, the artefacts, the smells, the sounds, were all brought together in these encounters bringing novel experiences and different meanings. Chernobyl Exclusion Zone has now become a commodified tourism product with available tourism services - transportation, accommodation, guiding, food provision and a souvenir shop, and for this reason it is discussed in light of commodification. Tourists now pay the money to purchase the tourism experience of being at the place of a major disaster. Furthermore, the intangibles (such as dystopia, tragic past or radiation) can also be said to be commodified and hence sold as part of the tourism experience in this context.

\section{The sense of sublime}


The Zone is often perceived as a place that is marginal and subliminal, that people fear and respect at the same time. For some reason, it indicates apocalyptic presumptions of death and renewal, which is perhaps why Goatcher and Brunsden (2011) suggest that there is a sense of the sublime in visiting Chernobyl. In this context, this notion is associated with the power of nature to be reborn and again take over despite the cataclysmic environmental disasters, as well as its immense power to prompt us to think about the meaning of our existence in this world. In the romantic poetry of William Wordsworth, the notion of 'sublime' was most often used to describe a range of unsettling experiences: from observations of the grand and terrifying in nature (floods, earthquakes, volcanoes or thunderstorms) to descriptions of the power and majesty of the divine (Shaw, 2007). Goatcher and Bunsden (2011) further explain that such "hazards elude the senses and descriptive language, and they remain un-grasped, but are nonetheless experienced" (p. 117). Escaping any attempt to be grasped or completely understood, the sublime may inspire terror, amazement, astonishment, stupefaction, as well as reverence and admiration (Burke, 2009). Sublime is also an epithet that stands for something that is unrepresentable, uncapturable and unphotographable (Garlick, 2002), such as radiation that wiped off the whole region. For Edensor such experiences are potentially transformative, they prompt us to think and feel in new ways. They have the power to make us ponder and look deep inside of us, of our existential being. Embodied in this environment, William could not describe with precision the way he felt about being there. The feelings transcended his known vocabulary:

"This surreality imparted a kind of haze over me. This is much deeper and harder to explain with words. I was both present and not. In that place but also in my head, and the image of what I knew and what I expected as well as what I could touch and see.”

"What was it like to be there", I asked, in an attempt to elicit a more particular answer:

"It was amazing to be there and to see it in real life having only known it as something from TV, film, books and video games. But feelings were mixed. The whole place had an energy about it... sorry to use the word energy. It is the energy of vacated space. The feeling that someone has just left the room. Or the feeling of an empty arena. Primed and filled with potential energy. But this energy is tinged with the feeling of things undone and unfinished. Of lives interrupted. It is the feeling that the phone is about to ring." 
In particular, the writing of a mural "What are we looking for?", that pictured a chair falling back from a table, made a big impression on William. The image itself related perfectly to his thoughts of things undone, of people just gone, or rooms only just vacated. It had much meaning for him, not just in the context of Chernobyl and Pripyat, it had a wider resonance in the context of our species and the way we think. The absent-presenceness and elusiveness of the experience (Goatcher \& Bundsen, 2011) were obvious in William's answer. The Exclusion Zone certainly looked like a job half-done, as if a big shift in its structure and function was taking place. It also looked both dead and alive at the same time. William was more precise in discussing the significance of humankind in the context of the multiverse, prompted by the creeping realisation that humans are only a small part of the ecosystem in the Zone, on the Planet and of everything (or nothing) that is, or exists, around us:

"I think too often we believe we are the centre of the universe, the most advanced of all things on this Earth, we forget that we are simply a small part of a much larger picture. We are a speck of dust in a column of light that shines through a cathedral window. We are not the light, we are not the window, we simply pass through it into non-existence. This may seem grim, but for me this is affirming. It is wonderful to be a part of something so complex and variegated, so mysterious and unknown."

"So, how would you describe this feeling?", I asked.

"In a phrase I would describe it as existential empathetic-sadness. Though I never experienced the disaster first hand, knowing full well, the known facts and having some idea of the impact on the people involved - still to this day being affected - the impressions gleaned speak volumes beyond the simple facts of the catastrophe and its impact but also of our (humanity's) impact upon ourselves and our planet. Are we arrogant to try and harness the power of the atom? Are we incredibly advanced? Or are we simply naïve and stupid? This links to my feelings on entering insomuch as making things into commodities and cheapening them if you will. The very act of our collective evolution has made us forget that we are simple, frail monkeys living in a highly sensitive eco-system with which we have no problem abusing and taking liberties."

The sense of sublime in Wordsworth's terms is usually linked to natural phenomena of which humans have fear. It is the undisputed power of nature that keeps us small and reminds us 
that we are merely a micro particle in the grand scheme of things. In the Zone, nature has proved this. Despite still being the most contaminated area on the planet, nature here seems to have not only survived high levels of radiation, but also flourished due to a significant reduction of human impact. The vegetation has adapted to the contaminated environment and found its way to dominate the landscapes. The Zone has become a 'radioecological reserve', a unique sanctuary for a wide range of plant and animal species. Storks, wild boars, lynx, fox, wolves, even bears have been reported in the area.

This prompted me to ask William in what ways he thinks nature is sublime and what meaning it has for him:

"Sublime for me is the handing over of humanity back to nature. Nature is sublime because we know of nothing else (unless you are religious) so to see it enveloping a city and its ill-fated nuclear plant is oddly comforting. It warns me and comforts me. I feel odd saying this, because it is odd to say it, I suppose. Maybe it reminds me that each one of us here fits into a place and time, for a reason or not."

He took a short pause, and then proceeded:

"Despite this sadness and my empathy for the people affected I also had this existential impression that, particularly after visiting Pripyat and its environs, we are small and insignificant in the face of such power. The power which we think can be harnessed but in practice has the potential to destroy us all. I felt a kind of gladness, almost contentment knowing that nature had reclaimed the exclusion zone and that it was flourishing only 30 years after humans had left. I reflected on our brief history in the context of the nature that surrounds us and the aeons for which it has superseded us and will indeed, succeed us. I had a tenuous feeling as if on the edge of doom, a looming cataclysm. I have a similar (though faint) feeling when thinking about the existence of black holes."

While the Zone stirs up the senses and triggers the feeling of the sublime, it has the immense power to give way to feelings of cultural anxiety inherent in the risk society (Podoshen, 2015b; Goatcher \& Brunsden, 2011). Being in the Zone, in a way, feels like stepping into a parallel, other world, the world in which chronological time is non-existent, which is proved by the stopped or handless clocks encountered inside some buildings. But one cannot help 
bringing the outside world to mind in such way to start questioning the existence of the humankind, the order of things or the structure of human life, even the will of political leaders. Stone (2013) suggests that Chernobyl, as a consequence of the outside, ordinary world with its political disorder and fragile societal frameworks, brings these thoughts to the fore. William shared this view:

"I had this feeling in the background, almost doom-like, a permeating sense. The town and the abandoned areas, they all have an apocalyptic feel about them. Perhaps it resonates now because of our current world. In the UK uncertainty and chaos, America and Europe going mad it seems and war and conflict as prevalent as ever elsewhere."

The tourist experience of Chernobyl transcends the primary reasons for visitation in its ability to augment the awareness of the mortality of humans and fragility of the modern world (Dobraszczyk, 2010). Thinking in more existential terms is a step beyond thinking about the tour itself; however the tour may bring these thoughts up. Ontological security, existential anxiety and questioning freedom in life are pervasive topics of the contemporary era. Humans have the fear and feel they are being threatened and watched by Orwell's Big Brother. William attempted to articulate his thoughts:

"I don't think it would be wrong to say that in the last ten years or so the amount of apocalyptic fiction has increased greatly. Look at the Black Mirror! Look at every modern zombie or horror film. They are fictions that play on our anxieties. We have a voyeuristic interest in the breakdown of society. Here it is in reality. The Exclusion Zone."

\section{Conclusions}

There is something about the power of ruins, abandoned places and disaster sites to trigger our thinking about natural processes and the fleetingness of life. Irrespective of the events that changed the course of their history, they continue to live. As Ljosland (2019) explains, abandonment, ruination and decay is not about stopping time, but about transforming into something else. Now when Chernobyl Exclusion Zone has opened up to tourism, it can show us how the time for it has not stopped, and that it is not dead at all - but very much alive. Post-disaster 'bare life' nonetheless goes on (Davies \& Polese, 2015). 
In this study I had my focus on visitor's embodied experiences of Chernobyl as a commodified dystopic tourism site. In general, tourists' lived experiences have been somewhat marginalised in dark tourism research. To confront this, I explored the ways in which tourists engage with the place and interpret their experiences. My intention here was to provide an account of a well-known disaster site, of which both researcher and informant were part, and they together, through interpretative phenomenological analysis, produced a narrative of the experience of the place. The embodied approach enabled me to more closely engage with both the research setting and my informant in more sustained, intimate way. Visiting the Zone together and keeping in touch afterwards provided a more natural context for subsequent discussions and reflections on the events and lived experiences. For this reason, IPA was a justifiably appropriate way to elicit meanings from conversations and derive some conclusions. Whilst singularity of the researched experience may be questioned and criticised, I have attempted to show how the approach taken has the immense potential to provide deeper and richer insights into multiple layers of the human experience and trigger thinking about the ontological question of existence. It is hoped that the study can contribute both to critical understandings of (human life through) tourism in more existentialist terms and to the dark tourism scholarship by offering new avenues for its explorations.

It is argued here that although the Zone has lately undergone the processes of 'touristification' and 'museumisation' (Stone, 2013) through the increasing number of tourist groups, and despite popularisation and commercialisation through the entertainment industry, the experience of the place defies banalisation. Whilst death and disaster can (to an extent) be commodified and sold to tourists, the powers of nature, or our response to thinking about them, cannot. These revelations have the potential to inform tourism planners about the ways in which tourism is to be managed in the Zone. Tours in Chernobyl go beyond the facts and the examination of disaster and artefacts. Tourists are able to engage in making sense of the processes, the aesthetics and the perception of dystopia, as well as to embrace the invisible (Podoshen et al, 2015, p. 324). It is then the task for tourism planners to think of novel ways of marketing and interpreting the dystopic tourist sites. Perhaps more attention should be paid to the effects of the environment on the sensory experiences in situ, highlighting feelings, sights, smells and sounds. Olfactory and haptic experiences of the place that was and still is contaminated by radioactivity, entering the abandoned buildings and towns that were once inhabited, imagining the taste of metal in the mouth and trying to understand the scale of the disaster, are truly spine-chilling and bring to the fore experiences and thoughts we might not 
be able to feel and have otherwise. This may deepen understanding of the place through the sensual engagement which may round out the tourism experience. In that sense, Martini and Buda's (2018) call for affective and emotional dimensions of the encounter in dark tourism studies should be answered. More embodied approaches should be taken in researching the lived experience within broader discourses of dark tourism. Unpacking the human body and taking into account its temporality, subjectivity, partiality and fluidity may add to debates about the situated knowledges of dark sites and dystopic places.

Buda et al (2014) mention adventure tourism as a potential avenue for future research of danger-zone tourism. Although they suggest risk narratives (as risk and danger have long been considered key qualities of adventure tourism) through which dark tourism experiences may be examined, these can be linked to and supplemented by, for example, discourses on existential comfort and ontological security. These are the dimensions of the adventure experience that Varley et al (2018) and Farkic (2018) speak about, as ontological feelings ground our existential being in this world. Perhaps this can be linked to the dark tourism discourse, as both in dystopic places as well as in wild nature people seek some form of adventure, and, through their embodiment, may be more inclined to question the ontological existence and existential belongingness to the place and to the world. Stone's (2010) doctoral thesis on death, dying and dark tourism in contemporary society tackles an issue of ontological security and these ideas should be therefore extended by dark tourism scholars. In general, dark tourism literature may benefit from interdisciplinary collaborative research, bringing into conversation scholars from across a range of disciplines including cultural geography, archaeology, performance studies, heritage studies, history and literature.

To be sure, in places like the Chernobyl Exclusion Zone, one can truly feel and understand how fragile life is, and how small we, human species, are. It is a funny thought though, that the concrete wall we encountered inside the Zone made us stop and think, by asking: What answers are we looking for here? William's final reflections were an attempt to, in some way, answer this question; however, they only prompted even more questions:

"Chernobyl is the result of rapid progress, of rapid work and trying to please bosses and trying to achieve deadlines and trying to achieve goals. But to what end? However big and proud and powerful a civilization, time and again history teaches us that it will fall. How many great powers were there before us? And how many will come after? This goes deep to those big questions about purpose and our very reason 
for being here. Our distinct lack of understanding as regards these questions. Our rush for progress, technology and exploration but still our lack of understanding as to why we are here to begin with. Though these thoughts are within me already, being in the exclusion zone made me reflect on them and I continue to reflect on them. Is our drive for progress misguided? As can be proven by the disaster. Or is it our whole purpose? What are we looking for? With these big thoughts going around in my head, I also felt contentment at the fact - and this may sound strange - that Chernobyl had happened. These events ground us. But they must also bring us together, so much as they inspire humanity and compassion. I have alluded to it previously, but it was nice to see that the world and nature will cope without us, it is nice to not be the centre of the universe. Am I saying it was humbling being there? It was not the power of the harnessed energy and the destruction that awes me, it is the infallible, incomprehensible power of nature and its existence that does this. Atomic civilization or no. Try as we might we are not good at playing God.

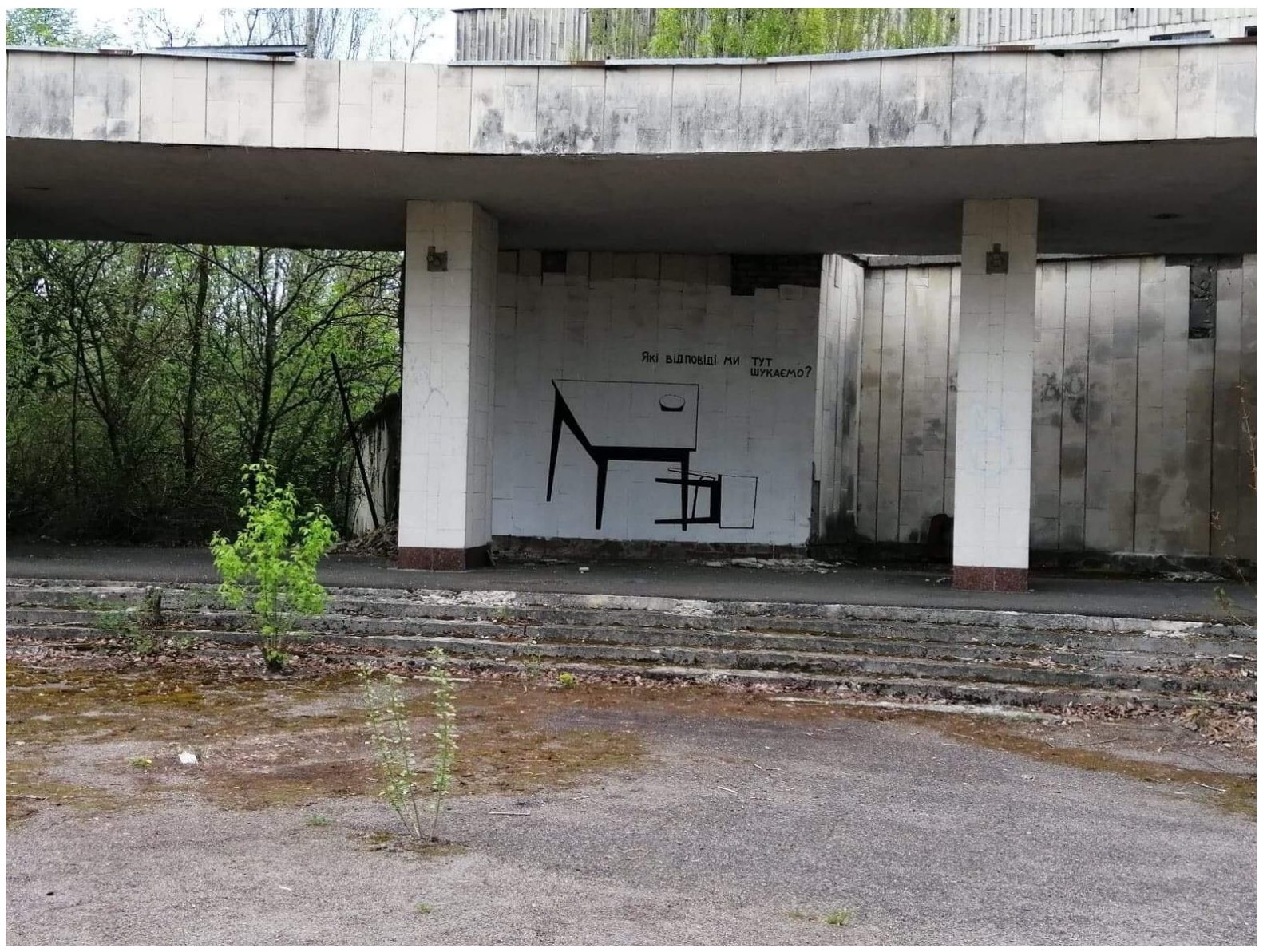

Figure 1. Graffiti on the wall in Pripyat. The writing asks: Які відповіді ми тут шукаємо? (What answers are we looking for here?) 


\section{References}

Beech, J. (2009). Genocide tourism. In R. Sharpley, \& P. R. Stone (Eds.), The darker side of travel: The theory and practice of dark tourism. Bristol: Channel View. 207-223.

Bissell, D. (2014). Encountering stressed bodies: Slow creep transformations and tipping points of commuting mobilities. Geoforum, 51, 191-201.

Boateng, H., Okoe, A. F., \& Hinson, R. E. (2018). Dark tourism: Exploring tourist's experience at the Cape Coast Castle, Ghana. Tourism Management Perspectives, 27, 104110.

Buda, D. M., d'Hauteserre, A. M., \& Johnston, L. (2014). Feeling and tourism studies. Annals of Tourism Research, 46, 102-114.

Buda, D. M., \& Shim, D. (2015). Desiring the dark: 'a taste for the unusual' in North Korean tourism?. Current Issues in Tourism, 18(1), 1-6.

Burke, E. (2009). A philosophical enquiry into the sublime and beautiful. Routledge.

Bürkner, D. (2014). The Chernobyl landscape and the aesthetics of invisibility. Photography and Culture, 7(1), 21-39.

Cole, T. (2000). Selling the Holocaust: From Auschwitz to Schindler: How history is bought, packaged and sold. New York: Routledge.

Davies, T., \& Polese, A. (2015). Informality and survival in Ukraine's nuclear landscape: living with the risks of Chernobyl. Journal of Eurasian Studies, 6(1), 34-45.

de Jong, A. (2017). Unpacking Pride's commodification through the encounter. Annals of Tourism Research, 63, 128-139.

Dobraszczyk, P. (2010). Petrified ruin: Chernobyl, Pripyat and the death of the city. City, 14(4), 370-389.

Dunkley, R., Morgan, N., \& Westwood, S. (2011). Visiting the trenches: Exploring meanings and motivations in battlefield tourism. Tourism Management, 32(4), 860-868.

Dunkley, R. A., Morgan, N., \& Westwood, S. (2007). A shot in the dark? Developing a new conceptual framework for thanatourism. Asian Journal of Tourism and Hospitality, 1(1), 5463.

Eatough, V., \& Smith, J. A. (2008). Interpretative phenomenological analysis. The Sage handbook of qualitative research in psychology, 179, 194. 
Edensor, T. (2016). Walking through ruins. In Ways of walking. Ethnography and practice on foot. Jo Lee Vergunst, Tim Ingold (Eds.). Routledge. pp. 135-154.

Edensor, T. (2007). Sensing the ruin. The Senses and Society, 2(2), 217-232.

Farkic, J. (2018). Outdoor guiding as hospitality work. Annals of Tourism Research, 73(C), 197-199.

Freeman, L. A. (2014). The Manhattan project time machine: Atomic tourism in Oak ridge, Tennessee. In B. Sion (Ed.), Death tourism: Disaster sites as recreational landscape. London: Seagull. 54-74.

Garlick, S. (2002) 'Revealing the Unseen: Tourism, Art and Photography', Cultural Studies 16(2): 289-305.

Goatcher, J. and Brunsden, V. (2011) Chernobyl and the Sublime Tourist. Tourist Studies, 11(2), 115-137.

Jaworowski, Z. (2010). Observations on the Chernobyl Disaster and LNT. DoseResponse, 8(2). 148-171.

Kennell, J., Šuligoj, M., \& Lesjak, M. (2018). Dark events: commemoration and collective memory in the former Yugoslavia. Event Management, 22(6), 945-963.

Kuchinskaya, O. (2014). The politics of invisibility: Public knowledge about radiation health effects after Chernobyl. MIT Press.

Langhof, J. G., \& Güldenberg, S. (2019). Pirates, ghosts and customer loyalty-Reviewing the dark ride experience. Tourism Management Perspectives, 31, 398-420.

Lennon, J. J., \& Foley, M. (2000). Dark Tourism: The Attraction of Death and Disaster. London: Continuum.

Lewis, C. (2008). Deconstructing grief tourism. The International Journal of the Humanities, 6(6), 165-169.

Light, D. (2017). Progress in dark tourism and thanatourism research: An uneasy relationship with heritage tourism. Tourism Management, 61, 275-301.

Ljosland, R. (2019). What makes ruination and decay attractive?, Retrieved from www.bit.ly/2Ct7k0R

Malone, S., McCabe, S., \& Smith, A. P. (2014). The role of hedonism in ethical tourism. Annals of Tourism Research, 44, 241-254.

Martini, A., \& Buda, D. M. (2018). Dark tourism and affect: framing places of death and disaster. Current Issues in Tourism, 1-14.

Miles, W. F. (2002). Auschwitz: Museum interpretation and darker tourism. Annals of Tourism Research, 29(4), 1175-1178. 
Miller, D. S., \& Gonzalez, C. (2013). When death is the destination: The business of death tourism e despite legal and social implications. International Journal of Culture, Tourism and Hospitality Research, 7(3), 293-306.

Modlin Jr, E. A., Alderman, D. H., \& Gentry, G. W. (2011). Tour guides as creators of empathy: The role of affective inequality in marginalizing the enslaved at plantation house museums. Tourist Studies, 11(1), 3-19.

Pernecky, T., \& Jamal, T. (2010). (Hermeneutic) phenomenology in tourism studies. Annals of Tourism Research, 37(4), 1055-1075.

Petryna, A. (2013). Life exposed: biological citizens after Chernobyl. Princeton University Press.

Pharino, C., Pearce, P., \& Pryce, J. (2018). Paranormal tourism: Assessing tourists' onsite experiences. Tourism Management Perspectives, 28, 20-28.

Podoshen, J. S., Yan, G., Andrzejewski, S. A., Wallin, J., \& Venkatesh, V. (2018). Dark tourism, abjection and blood: A festival context. Tourism Management, 64, 346-356.

Podoshen, J. S., Andrzejewski, S. A., Venkatesh, V., \& Wallin, J. (2015a). New approaches to dark tourism inquiry: A response to Isaac. Tourism Management, 51, 331-334.

Podoshen, J. S., Venkatesh, V., Wallin, J., Andrzejewski, S. A., \& Jin, Z. (2015b). Dystopian dark tourism: An exploratory examination. Tourism Management, 51, 316-328.

Podoshen, J. S., Venkatesh, V., \& Jin, Z. (2014). Theoretical reflections on dystopian consumer culture: Black metal. Marketing Theory, 14(2), 207-227.

Podoshen, J. S. (2013). Dark tourism motivations: Simulation, emotional contagion and topographic comparison. Tourism Management, 35, 263-271.

Robbie, D. (2008). Touring Katrina: Authentic identities and disaster tourism in New Orleans. Journal of Heritage Tourism, 3(4), 257-266.

Sharpley, R. (2009). Shedding light on dark tourism: An introduction. In R. Sharpley, \& P. R. Stone (Eds.), The darker side of travel: The theory and practice of dark tourism. Bristol: Channel View. 3-22.

Shaw, P. (2007). The sublime. Routledge.

Smith, J. (2008). Qualitative psychology: A practical guide to research methods (2nd ed.). London: Sage Publications.

Smith, J. A. (2004). Reflecting on the development of interpretative phenomenological analysis and its contribution to qualitative research in psychology. Qualitative Research in Psychology, 1(1), 39-54.

Smith, J. A. (1996). Beyond the divide between cognition and discourse: Using interpretative phenomenological analysis in health psychology. Psychology and Health, 11(2), 261-271. 
Smith, J.A., Flowers, P. \& Larkin, M. (2009). Interpretative Phenomenological Analysis. London: Sage.

Smith, J.A. and Osborn, M. (2003). Interpretative phenomenological analysis. In J.A. Smith (ed.), Qualitative Psychology. A Practical Guide to Research Methods (pp. 51- 80). London: Sage.

Smith, J. A., Jarman, M., \& Osborn, M. (1999). Doing interpretative phenomenological analysis. Qualitative Health Psychology: Theories and Methods, 218-240.

Stone, P. R (2013). Dark Tourism, Heterotopias and Post-Apocalyptic Places: The Case of Chernobyl. In L.White \& E. Frew (Eds.) Dark Tourism and Place Identity. Melbourne: Routledge.

Stone, P. R. (2012). Dark tourism and significant other death: Towards a model of mortality mediation. Annals of Tourism Research, 39(3), 1565-1587.

Stone, P. R. (2010). Death, dying and dark tourism in contemporary society: A theoretical and empirical analysis (Doctoral dissertation). University of Central Lancashire. UK.

Stone, P. (2006). A dark tourism spectrum: Towards a typology of death and macabre related tourist sites, attractions and exhibitions. Tourism, 52, 145-160.

Strange, C., \& Kempa, M. (2003). Shades of dark tourism: Alcatraz and Robben Island. Annals of Tourism Research, 30(2), 386-405.

Varley, P., Farkic, J., \& Carnicelli, S. (2018). Hospitality in wild places. Hospitality \& Society, 8(2), 137-157.

Virilio, P. (2007) The Original Accident. Cambridge: Polity.

Wilson, E., \& Hollinshead, K. (2015). Qualitative tourism research: Opportunities in the emergent soft sciences. Annals of Tourism Research, 54, 30-47.

Yan, B.-J., Zhang, J., Zhang, H.-L., Lu, S.-J., \& Guo, Y.-R. (2016). Investigating the motivation-experience relationship in a dark tourism space: A case study of the Beichuan earthquake relics, China. Tourism Management, 53, 108-121.

Yankovska, G., \& Hannam, K. (2014). Dark and toxic tourism in the Chernobyl exclusion zone. Current Issues in Tourism, 17(10), 929-939 